\title{
Facile Method for the Synthesis of Copper Nanoparticles Supported on the Organoclay Material
}

\author{
Mokae Fanuel Bambo',2, Rui Werner Marcedo Krause3 ${ }^{3}$, Richard Motlhaletsi Moutloali² \\ ${ }^{1}$ Advanced Materials Division, DST/Mintek Nanotechnology Innovation Centre, Mintek, South Africa \\ ${ }^{2}$ DST/Mintek Nanotechnology Innovation Centre-UJ Water Node, Department of Applied Chemistry, University of \\ Johannesburg, Johannesburg, South Africa \\ ${ }^{3}$ Department of Chemistry, Rhodes University, Grahamstown, South Africa \\ Email: mokaeb@mintek.co.za
}

How to cite this paper: Bambo, M.F., Krause, R.W.M. and Moutloali, R.M. (2017) Facile Method for the Synthesis of Copper Nanoparticles Supported on the Organoclay Material. Journal of Biomaterials and Nanobiotechnology, 8, 144-158. https://doi.org/10.4236/jbnb.2017.82010

Received: September 30, 2016

Accepted: April 25, 2017

Published: April 28, 2017

Copyright (c) 2017 by authors and Scientific Research Publishing Inc. This work is licensed under the Creative Commons Attribution International License (CC BY 4.0).

http://creativecommons.org/licenses/by/4.0/

\section{Open Access}

\begin{abstract}
In this study, synthesis of copper nanoparticles was performed using organoclay as a support to stabilize the nanoparticles. Organoclay amount was gradually increased, which had an effect on the morphology of the resultant nanoparticles. Low amount of organoclay added resulted in larger and agglomerated copper nanoparticles whereas increased amount of organoclay gave smaller sized nanoparticles. The hybrid materials were characterized using the SEM and TEM for morphology, XRD and FT-IR spectroscopy for structural elucidation, thermal analysis using TGA and also studying their antibacterial effect on the two well-known gram negative bacteria of $E$. coli and $P$. Aeruginosa. The synthesized nanoparticles were found to be crystalline $\mathrm{Cu}$ nanoparticles with a mix of $\mathrm{CuO}$. Larger sized copper nanoparticles and agglomerates showed the higher thermal behaviour as compared with smaller nanoparticles with higher organoclay loading. The hybrid showed an improved antibacterial activity as compared with organoclay alone. The hybrid showed the higher antibacterial effect against the $P$. aeruginosa microorganism as compared with the $E$. coli microorganism.
\end{abstract}

\section{Keywords}

Organoclay, Copper Nanoparticles, Hybrid, Microorganisms

\section{Introduction}

Since the exploitation of nanotechnology, synthesis of nanoparticles has been the heart of nanotechnology research. With various methods of nanoparticles synthesis been developed to exploit this field of research, number of nanomaterials 
can be found in many applications at the moment. The synthesis of nanoparticles is of interest due to their wide variety of applications in fields such as electronics [1] [2], photonics [3] [4] [5], catalysis [6] [7] [8], medicine [9] [10] and water treatment [11] [12] [13], etc. The fundamental aim of their synthesis is the ability to control the size and shape of atomic clusters or nanoparticles and their ordering in 1D, 2D, or 3D arrays. Studies have shown that the size, morphology, stability and chemical and physical properties of the metal nanoparticles are influenced strongly by the experimental conditions, the kinetics of interactions of metal ions with reducing agents, and adsorption processes of stabilizing agent with metal nanoparticle [14]. The most known conventional chemical route for the synthesis of nanoparticles involved the reduction from the appropriate salt solution, excess reducing agents such as sodium citrate [15] or $\mathrm{NaBH}_{4}$ [16] [17] and the stabilizing agent to stabilized nanoparticles in solution in order to prevent aggregation. The stabilization, in general, takes place by the absorption of electric charges on the surface, leading to a repulsion of the nanoparticles as long as a critical distance maintained [18]. Generally, specific control of the shape, size and distribution of the produced nanoparticles is achieved by changing the methods of synthesis, reducing and stabilizing agent factors. The chemical methods such as chemical reduction, micro-emulsions, thermal decomposition and electrochemical synthesis are widely used due to ease of control, simplicity of operation, limited equipment requirement and high quality of particles. Although nanoparticles can be made using various physicochemical methods [19], their synthesis using nontoxic and environmentally benign methods is attractive especially if they are intended to be used in applications such as water treatment or in human.

In particular, copper nanoparticles have been used with promising results as bactericides [20] [21] [22], antimicotics [23] [24] [25], and anticancer agents [26] [27] [28]. Umer et al. reported on selected methods used for the synthesis of copper nanoparticles either by using a chemical or physical synthesis route [29]. Recent work by other authors in the synthesis of copper nanoparticles has been either replacing the reducing agent or the stabilizing agent with an inexpensive or less/non-toxic material such as natural clay. Clay is known to be an inexpensive mineral and it is extensively used as filler in a number of composite materials. Drelich et al. prepared vermiculite decorated with copper nanoparticles as novel antibacterial materials [30]. Fusion of metallic nanoparticles in the structure of aluminosilicates is a relatively new approach in the synthesis of nanoparticles, few reports have been presented thus far on this topic. Hundakova presented the synthesis of silver and copper vermiculites and tested their antibacterial effects against the two bacterial groups [31]. The method still follows the wet chemical process but vermiculite is used to stabilize the nanoparticles. Hundakova also studied the stability of silver and copper on clay minerals (montmorrilonite) and vermiculite substrate in an aqueous environment and their antibacterial effect. Organoclay minerals represent a good candidate to prepare metal nanoparticles which are stable and are anchored on the clay substrate. 
In this study, the nanoparticle growth substrate comes from a known commercial compound of organo-montmorillonite, commercially known as Cloisite 30B. This montmorillonite is modified with methyl, tallow, bis-2 hydroxyethyl, quaternary ammonium, where tallow is $65 \% \mathrm{C}_{18}, 30 \% \mathrm{C}_{16}$, and $5 \% \mathrm{C}_{14}$. We present results on the synthesis of copper nanoparticles using this organoclay as a substrate surface for the synthesis of the nanoparticles. Study the effect of increasing the organoclay in the solution on the resultant nanoparticles. We have characterized the resulting nanoparticles by SEM, TEM, XRD and FT-IR spectroscopy, TGA and study their antibacterial effect on the two well-known gram negative bacteria of Escherichia coli and Pseudomonas aeruginosa. To the best of our knowledge, this is the first report in the literature on copper nanoparticle synthesis using commercially available organoclay such as Cloisite 30B.

\section{Materials and Methodology}

\subsection{Materials}

Cupric sulphate pentahydrate $\left(\mathrm{CuSO}_{4} \cdot 5 \mathrm{H}_{2} \mathrm{O}\right)$ and tri-Sodium Citrate $\left(\mathrm{Na}_{3} \mathrm{C}_{6} \mathrm{H}_{5} \mathrm{O}_{7}\right)$ were purchase from Associated Chemical Enterprises (ACE, South Africa). Sodium borohydride powder $\left(\mathrm{NaBH}_{4}\right)$ was obtained from Sigma-Aldrich Chemical Co. (South Africa). The organically modified clay, Cloisite 30B (Organoclay) obtained from Southern Clay Products (USA) was used as a substrate. Cloisite $30 \mathrm{~B}$ is a montmorillonite organically modified with dimethyl-dihydrogenated tallow quaternary ammonium, in a concentration of $90 \mathrm{meq} / 100 \mathrm{~g}$ clay. The solvent used is N,N-dimethyl acetamide (DMAc) purchased from Sigma-Aldrich Chemical Co. (South Africa).

\subsection{Microorganisms}

The antibacterial activity of prepared nanocomposites was determined using two gram negative bacterial strains of Escherichia coli (E. coli) was obtained from Centre for Metal Drug Discovery (CMDD) group at Mintek and Pseudomonas aeruginosa ( $P$. aeruginosa) was obtained from Biolabels group at Mintek.

\subsection{Synthesis of Copper Nanomaterials}

Copper nanoparticles were prepared following a modified method of Samim et al. [32]. In the current preparation, the stabilizing agent, $\mathrm{Na}_{3} \mathrm{C}_{6} \mathrm{H}_{5} \mathrm{O}_{7}$, was replaced with organoclay, acting both as a stabilizer and substrate for nanoparticles. To a solution of $\mathrm{CuSO}_{4} \cdot 5 \mathrm{H}_{2} \mathrm{O}$ in $100 \mathrm{~mL}$ distilled water, $1 \%$ organoclay was added while vigorously stirring at room temperature, stirring was continued for an hour under nitrogen $\left(\mathrm{N}_{2}\right)$ atmosphere. Similar reactions were prepared with $\mathrm{CuSO}_{4} \cdot 5 \mathrm{H}_{2} \mathrm{O}$ solution kept constant, with the addition of increased loading of the organoclay (i.e.; $2 \%-5 \%$ ). A solution of $\mathrm{NaBH}_{4}$ in distilled water was slowly added to the mixture, with stirring continued for an hour. The resultant solution was then centrifuged and organoclay/Cu nanoparticle hybrid was then air dried and room temperature. Table 1 details the conditions/amounts used for the assynthesis organoclay/Cu nanoparticles. 
Table 1. Composition of the prepared copper sulphate and organoclay solution and their designated names.

\begin{tabular}{ccc}
\hline $0.075 \mathrm{M} \mathrm{CuSO}_{4} \cdot 5 \mathrm{H}_{2} \mathrm{O}$ & Organoclay added (\%) & designated name \\
\hline 100 & 1 & $\mathrm{CloCu}-1(\mathrm{~A})$ \\
100 & 2 & $\mathrm{CloCu}-2(\mathrm{~B})$ \\
100 & 3 & $\mathrm{CloCu}-3(\mathrm{C})$ \\
100 & 4 & $\mathrm{CloCu}-4(\mathrm{D})$ \\
100 & 5 & $\mathrm{CloCu}-5(\mathrm{E})$ \\
\hline
\end{tabular}

\subsection{Instrumentation}

Scanning electron microscopy (SEM) [FEI Novanano230, Netherlands] was employed to observe the morphology of the organoclay/Cu hybrid nanoparticles. The instrument is equipped with an X-ray energy dispersive spectroscopy system (EDS) [AMETEK GmbH, Germany] for compositional analysis. The high resolution Transmission Electron Microscope (TEM) [JEOL JEM 2100F, United Kingdom] was used to determine the morphology of the organoclay and nanoparticles. Information about the phases and crystallinity was obtained using the Bruker D8 X-Ray Diffraction (XRD) [Bruker, South Africa] patterns which were recorded in the diffraction angular range $5^{\circ}-80^{\circ} 2 \theta$ using a Bruker Advance 8 diffractometer, working in the reflection geometry and equipped with a graphite monochromator on the diffracted beam (CoK $\alpha$ radiation). FTIR spectroscopy analysis was performed on a PerkinElmer Spectrum 2000 spectrophotometer [PerkinElmer, South Africa] with a resolution of $1 \mathrm{~cm}^{-1}$. Infrared spectra were obtained for the organoclay and organoclay-copper nanoparticles from 600 $4000 \mathrm{~cm}^{-1}$ using attenuated total internal reflection (ATR). The thermal stability of the synthesized polymer nanocomposite was carried out with a Simultaneous Thermal Analyser (STA) [Netzsch STA 429 Netzsch-Gratebau GmbH, Germany] by heating in nitrogen atmosphere from $25^{\circ} \mathrm{C}$ to $1000^{\circ} \mathrm{C}$ with heating rates $10^{\circ} \mathrm{C} / \mathrm{min}$. Heating was followed under a continuous nitrogen purge of 20 $\mathrm{mL} / \mathrm{min}$.

\subsection{Antibacterial Testing}

The antibacterial activity of the organoclay/Cu was tested against the two gram negative bacteria of $E$. coli and $P$. aeruginosa microorganism zone of inhibition (ZOI) method. This is a simple method of measuring the efficiency of an antibacterial agent against the above mentioned bacterial growth. The suspension of the bacteria cultures were prepared as follows: the Rapid E. coli chromogenic agar powder was used as a culture medium for E. coli bacterial growth and Pseudomonas chromogenic agar powder was used as culture medium for the $P$. aeruginosa bacterial growth. The $37 \mathrm{~g}$ of each of the agar was dissolved in $1000 \mathrm{ml}$ of distilled water; then the clear brown solvent was obtained. Both agar media were then sterilized at $120^{\circ} \mathrm{C}$ for $60 \mathrm{~min}$ in autoclave and then cooled to room temperature, briefly $20 \mathrm{~mL}$ of each of the agar medium was poured onto disposable 
sterilized Petri dishes and allowed to solidify. The surfaces of the solidified agar plates were allowed to dry in the incubator prior to streaking of microorganisms onto the surface of the agar plates. Next, $100 \mu \mathrm{L}$ of the microbial culture suspension in broth containing colony was streaked over the dried surface of the agar plate and spread uniformly using a sterilized plastic rod and allowed to dry before loading the hybrid materials as disks. The organoclay/Cu hybrid materials were made into $3 \mathrm{~mm}$ disks. The loaded disks were applied carefully to the surface of the seeded agar plates using sterile forceps. The diameters of the zones of inhibition were measured after $24 \mathrm{~h}$ of incubation at $37^{\circ} \mathrm{C}$.

\section{Results and Discussions}

\subsection{SEM and EDS Results}

Organoclay/Cu nanoparticles were successfully synthesized using chemical reduction method. The introduction of $\mathrm{NaBH}_{4}$ solution, acting as a reducing agent, caused the reaction colour to change from blue to dark brown which is an indication of the formation of $\mathrm{Cu}$ nanoparticles. The effect of organoclay on the size, shape, stability and antibacterial properties of the synthesized organoclay/ $\mathrm{Cu}$ hybrid nanoparticles was evaluated. Prior to testing the nanocomposites for antibacterial effect, they were subjected to different characterization methods to determine their physical and chemical properties. In this instance, SEM was used to study the morphology of organoclay/Cu hybrid nanoparticles and distributions of nanoparticles on the surface of the organoclay. Figure 1 shows the organoclay decorated with copper nanoparticles in forming these hybrids under SEM observation. Figure 1(a) exhibits the SEM image of layered organoclay particles, with some traces of lumped particles observed forming bulky micronsized aggregates.

As the organoclay amount is increased from $1 \%-5 \%$, less agglomerated particles are distributed on the organoclay surface as seen on the images. This shows that increased organoclay content provides more surface for nanoparticles to form and therefore are separated enough to minimize agglomeration to some degree. The agglomerates are also mostly observed when they are not formed on the organoclay surfaces. This confirms that the organoclay acts as a good support for nanoparticles formation allowing good dispersion of nanoparticles on the surface.

Energy Dispersive X-Ray Spectroscopy (EDS) analysis from each of the SEM images confirms that the organoclay composition is dominated by $\mathrm{C}, \mathrm{O}, \mathrm{Si}$ and $\mathrm{Al}$ peaks, with minor peaks of $\mathrm{Mg}$ and $\mathrm{Fe}$ observed, representing the structure of the organoclay moiety in the hybrid. Similar peaks were reported by Bhattacharya and Mandot [33]. Cu nanoparticles peaks are also observed in the spectrum which confirms the presence of the copper nanoparticles in these hybrid materials. No other chemical composition was detected in the samples signifying the purity of the as-synthesized nanoparticles.

Confirmation of the size of copper nanoparticles was achieved through the TEM analysis. Figure 2 shows the TEM micrographs of the organoclay/Cu hy- 

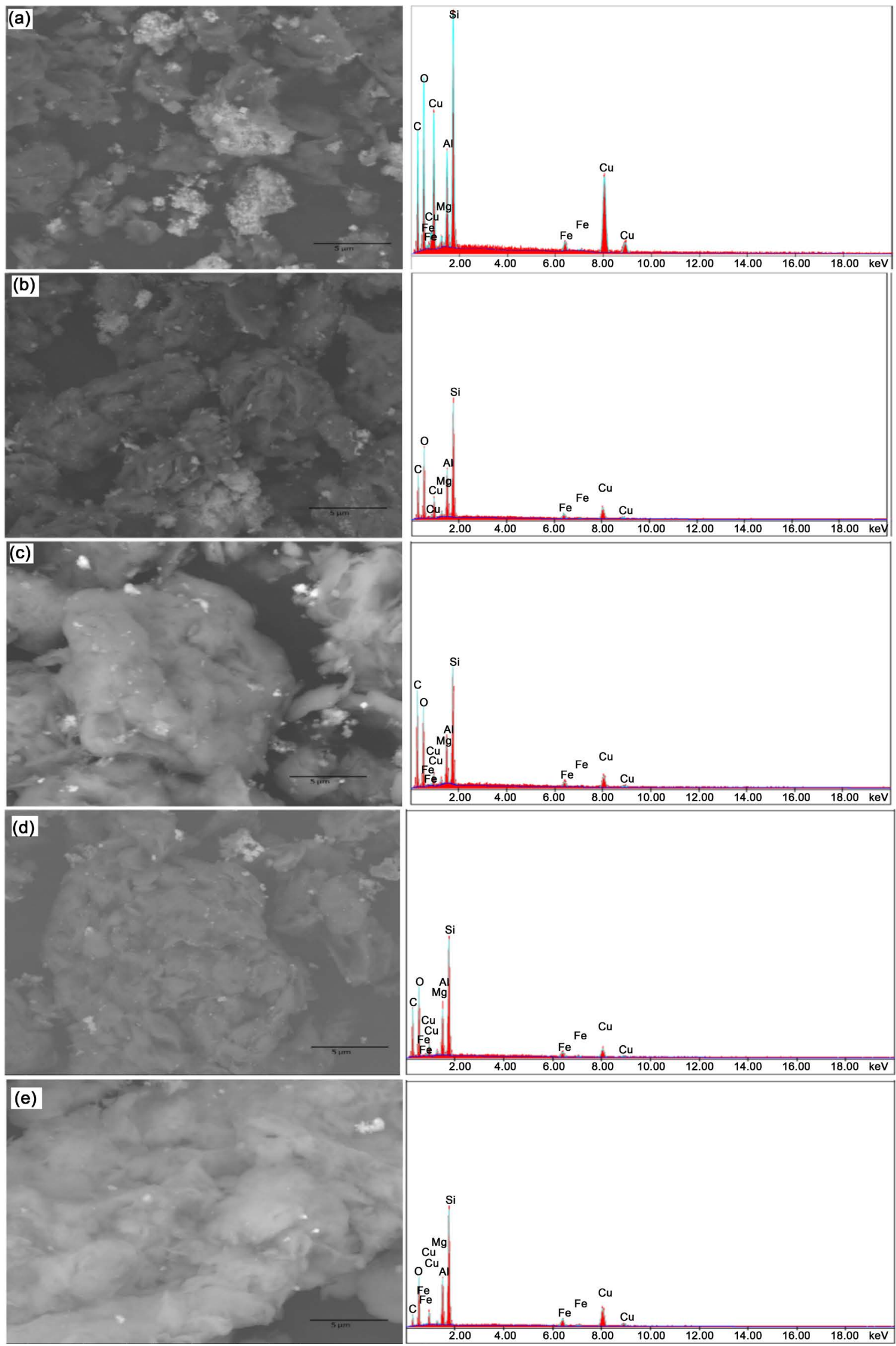

Figure 1. SEM micrograph and EDS analysis of the as-synthesized organoclay/Cu nanoparticles hybrid material. 

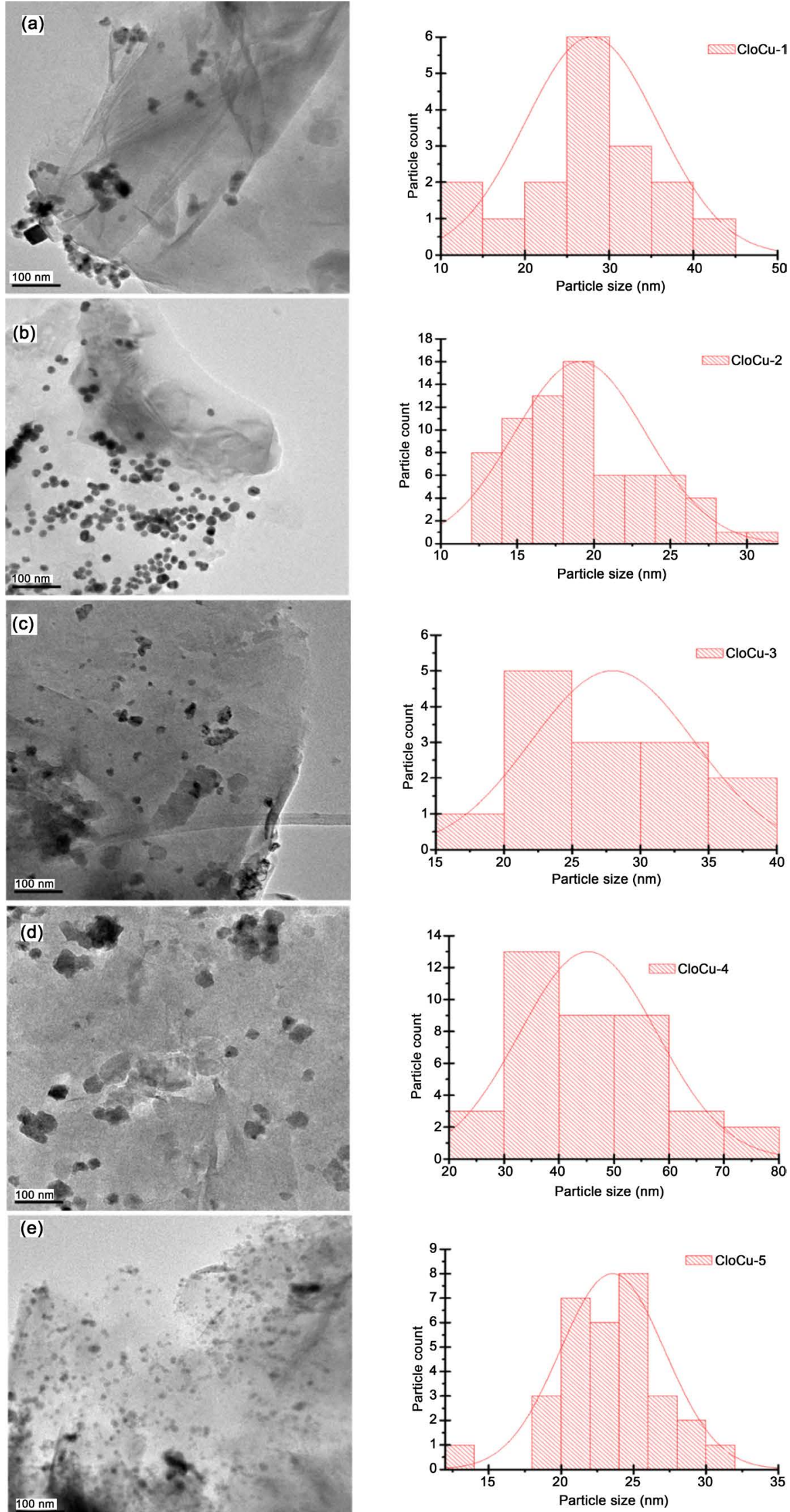

Figure 2. TEM micrograph of the as-synthesized organoclay/Cu nanoparticles hybrid material. 
brid materials (A-E). The images show that the copper nanoparticles are supported on the organoclay surface as observed in the SEM analysis. As stated previously from the SEM images, the supported nanoparticles are less aggregated. The organoclay platelets can be seen on these TEM images. Particle size distribution of the nanoparticles supported on organoclay is given alongside each respective micrographs with an average size ranging from $10-80 \mathrm{~nm}$ for the copper nanoparticles. Increasing organoclay leads to a slight decrease in the average copper nanoparticles size as well as leading to less agglomeration.

\subsection{XRD Studies}

The crystal structure of the nanoparticles was verified using XRD technique. According to Figure 3, peaks observed at $2 \theta$ values of $42.5^{\circ}, 51^{\circ}$ and $74^{\circ}$ correspond to (111), (200) and (220) planes of metallic $\mathrm{Cu}$ as shown by the CuNPs spectra in the figure. These three peaks were consistent with those of the standard JCPDS card No. 04-0836 for the standard spectrum of the pure fcc metallic $\mathrm{Cu}$ which has been observed at the following $2 \theta$ values; $43.297^{\circ}$ (111), $50.433^{\circ}$ (200) and $74.130^{\circ}(220)$, respectively, as reported earlier [34] [35]. Beside the metallic $\mathrm{Cu}$ peaks, more peaks are also observed on the spectra at $2 \theta$ values of $46^{\circ}$ and $59^{\circ}$, these are reported to correspond to (200) and (220) of $\mathrm{Cu}_{2} \mathrm{O}$, respectively, indication of the formation of copper (I) oxide nanocrystals [36] [37] [38]. From the organoclay/Cu hybrids (Figure 3) it can be observed that the metallic copper peaks appears at the same position as CuNPs spectra. Spectra A shows the high intensity peak of the (200) reflection of the $\mathrm{Cu}$ metallic nanoparticles. Increasing the organoclay into the hybrid result in reduced intensity of the (111) reflection peak (B-D) and a slight increase at E. The broadening of the peak in the XRD pattern indicates the presence of small nanocrystals of the copper [39]. The XRD has confirmed the formation of the $\mathrm{Cu}$ nanoparticles in the organoclay and also indicated the crystal structure of the nanoparticles formed. The resultant nanoparticles are a mixture of metallic $\mathrm{Cu}$ and $\mathrm{Cu}(\mathrm{I})$ oxide nanoparticles. Other peaks observed are as a result of the organoclay presence in the mixture. The (001) reflection peak of the organoclay at $2 \theta$ value of $4.9^{\circ}$ is shown as an inset (i) in the figure. This is in agreement with the work by Petrova et al. [40], who reported the appearance of (001) reflection peak at $2 \theta$ value of $4.9^{\circ}$. $\mathrm{XRD}$ analysis is not just another tool for confirming the presence of copper nanoparticles in the organoclay, but also determines the structure or even confirm whether organoclay was intercalated or exfoliated as the characteristics peak changes with galley height (or spacing between the silicate layers) of the organoclay. If the hybrid formed in the synthesis has intercalated structure, the XRD peak is seen at larger $\mathrm{d}$-spacing than the original organoclay or results in peak broadening. However, if a completely exfoliated structure forms in the hybrid, no peak is observed at the position. However, for all the organoclay/Cu hybrids synthesized the intensity of (001) peak was observed in all the spectra and is enhanced as the amount of organoclay is increased. For sample $\mathrm{C}$ and $\mathrm{E}$, the peak was observed to have decreased in intensity and broadening effect can be 
seen. As noted, there seem to be some degree of intercalation in the organoclay galleries. Since small particles of the copper nanoparticles are observed as organoclay is increased, this can be that the particles are deposited in the interlayer galleries resulting in decrease and broadening. But the same cannot be said for $\mathrm{D}$, which shows an increased intensity of the (001) reflection peak with no shift. The diffraction peak remained unchanged, this essentially indicates that equilibrium shift between exfoliation and intercalation structures in the hybrid was not experienced in the A, B and D samples during the synthesis process.

\subsection{FTIR Studies}

An additional confirmatory test was performed by studying the molecular interaction between the organoclay and the synthesized copper nanoparticles using FT-IR technique. Figure 4 shows the spectra of the organoclay/Cu hybrid materials at different organoclay loadings. The FT-IR spectra for organoclay normally show Al-O vibrations bands at 624, 792, 842 and $915 \mathrm{~cm}^{-1}$ confirm the presence of organoclay in the organoclay/Cu dispersions. The Si-O stretching peaks can be seen at 1080 and $1030 \mathrm{~cm}^{-1}$, with $\mathrm{Si}-\mathrm{O}$ bending peaks appearing at $520 \mathrm{~cm}^{-1}$,
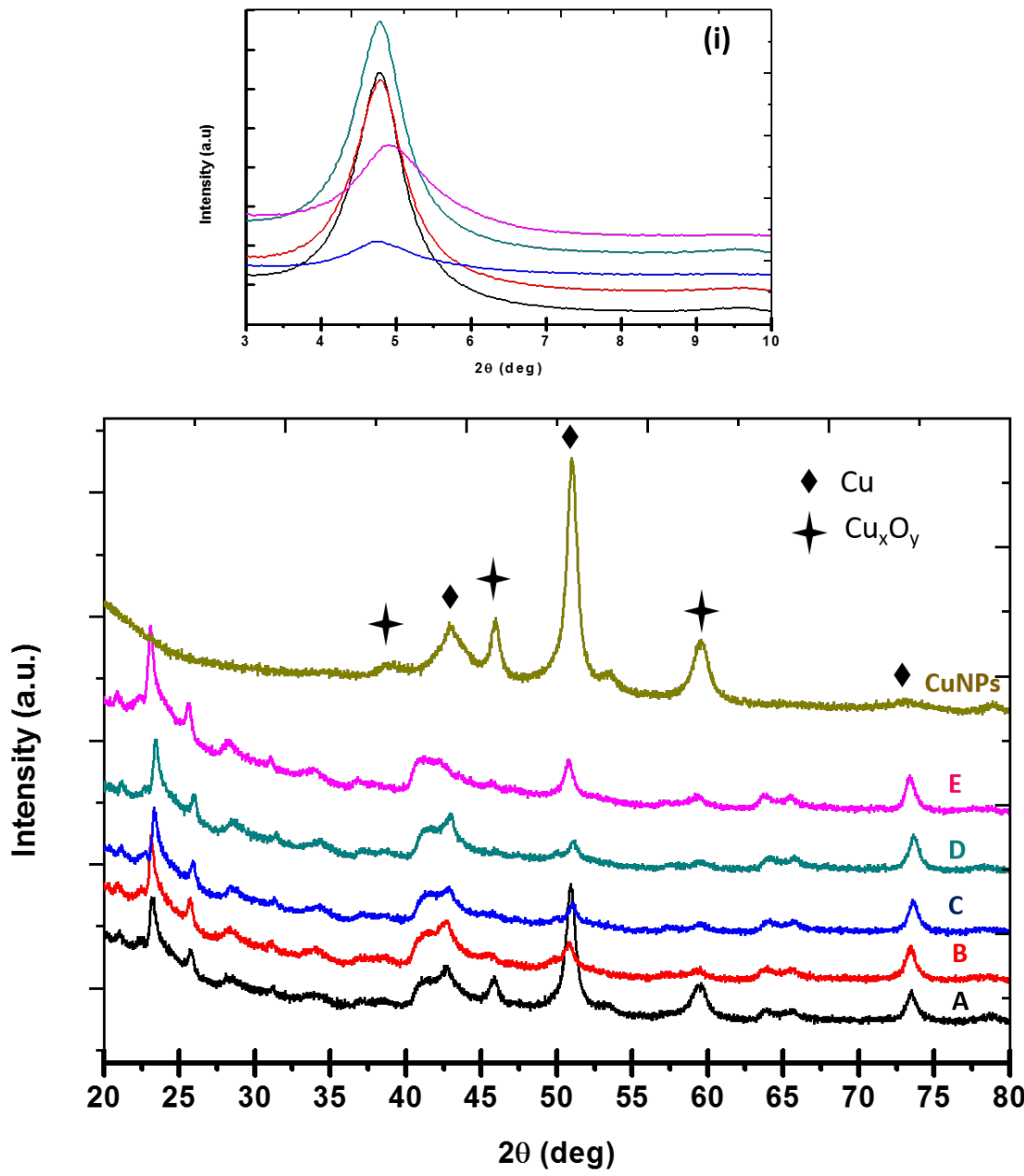

Figure 3. XRD spectra to study the crystalline nature of the as-synthesized organoclay/Cu nanoparticle hybrid material. 


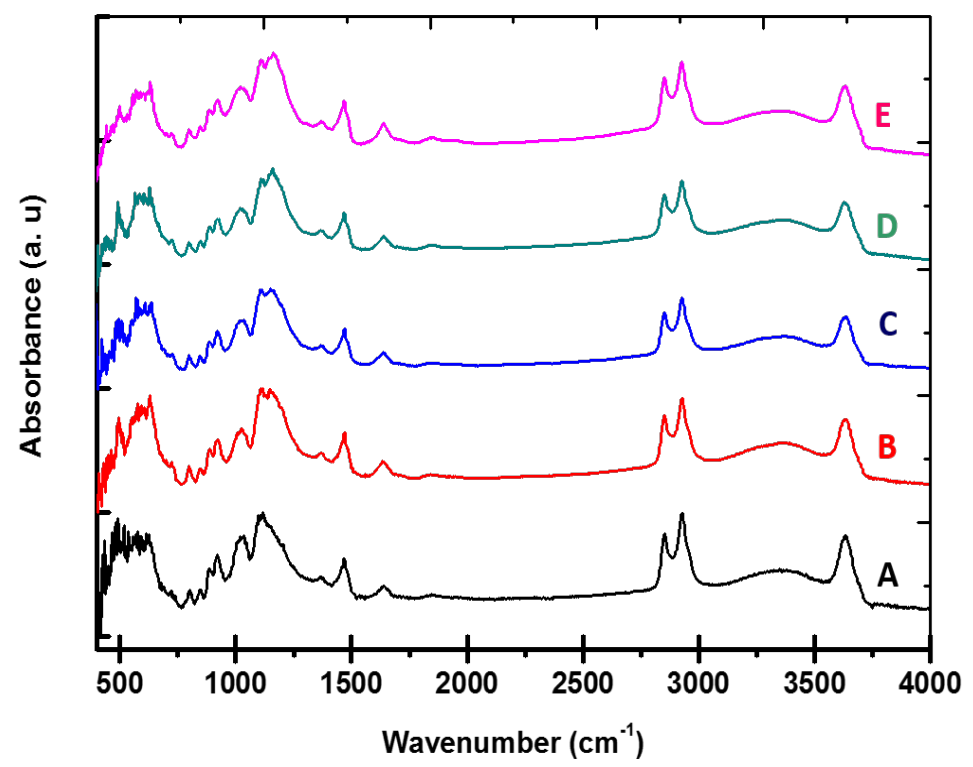

Figure 4. FT-IR spectra of the as-synthesized organoclay/Cu nanoparticles hybrid material.

as observed previously by Hadj-Hamou et al. [41]. Sharp peak at $3600 \mathrm{~cm}^{-1}$ illustrates $\mathrm{Si}-\mathrm{O}-\mathrm{H}$ stretching on surface of the clay. Peaks at 2900, 2840 and $1470 \mathrm{~cm}^{-1}$ show asymmetric, symmetric and bending stretching of $\mathrm{C}-\mathrm{H}$ bonds in- $\mathrm{CH}_{2}$ group of the organic modifier, respectively, in addition to in-plane scissoring vibrations. $\mathrm{Al}-\mathrm{OH}$ stretching peak appears at $920 \mathrm{~cm}^{-1}$, while peak at $1040 \mathrm{~cm}^{-1}$ represents $\mathrm{Si}-\mathrm{O}$ and $\mathrm{Si}-\mathrm{O}-\mathrm{Si}$ stretching. Broad peaks at 3390 and $1640 \mathrm{~cm}^{-1}$ indicate $\mathrm{H}-\mathrm{O}-\mathrm{H}$ stretching and $\mathrm{O}-\mathrm{H}$ bending, respectively. The intensities of the peaks at 3600 and $1040 \mathrm{~cm}^{-1}$ become enhanced as the organoclay loading is increase indicating greater loading of organoclay in the organoclay/Cu hybrid samples. Peaks in the range of $1374-1465 \mathrm{~cm}^{-1}$ correspond to $\mathrm{N}-\mathrm{H}$ bending in the surfactant used for organo-modification of the clay. Confirmation of FTIR spectra revealed vibration of the $\mathrm{CuO}$ band below $500 \mathrm{~cm}^{-1}$; a band at $624 \mathrm{~cm}^{-1}$ was attributed to some other form of $\mathrm{Cu}$ nanoparticles as observed in the XRD spectra [42].

\subsection{TGA Analysis}

The weight percentages of copper nanoparticles-organoclay hybrids were determined by TGA analysis under inert $\left(\mathrm{N}_{2}\right)$ atmosphere in each of the as-synthesized hybrid materials (A-E) as shown in Figure 5. The thermograms of the organoclay/Cu shows weight-loss events as follows; the first event is located in the temperature range between $200^{\circ} \mathrm{C}$ and $300^{\circ} \mathrm{C}$ that can be attributed to water evaporation and volatiles compounds and where significant weight loss of organoclay modifier compound is most apparent is known as maximum degradation temperature. The second stage of material loss is between $300^{\circ} \mathrm{C}$ and $420^{\circ} \mathrm{C}$ and is assigned to the degradation of clay modifier and some pyrolytic carbon found in the clay material. The third stage of material loss can be attributed to the softening of the metal nanoparticles. Similar loss was previously reported by 


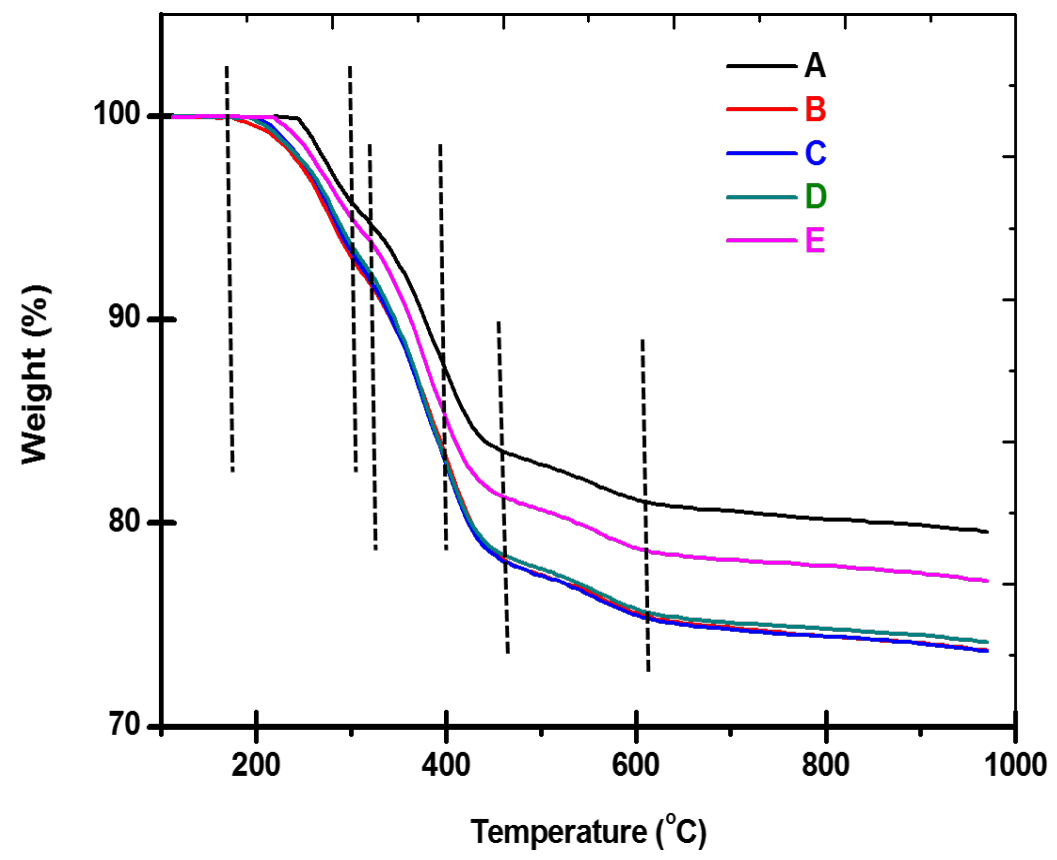

Figure 5. TGA curves of the as-synthesized organoclay/Cu nanoparticles hybrid material.

Kobayashia et al. [43]. The TGA profile for all the organoclay/Cu is almost similar in their degradation profiles, with the lower organoclay loading sample (A) showing higher thermal stability and also higher decomposed char residue. This can be attributed to the higher copper content of agglomerates. As the organoclay loading is increased, higher organoclay loading (E) also shows high thermal stability due to the high organoclay content in the hybrid.

\subsection{Antibacterial Studies}

The organoclay stabilized copper nanoparticles exhibited both antibacterial activities against Gram-negative bacteria of $E$. coli and $P$. aeruginosa. The organoclay material supported the efficiency of the synthesized copper nanoparticles. As shown in Figure 6, the antimicrobial activity (indicated by the zones of inhibition) of organoclay/ $\mathrm{Cu}$ nanoparticles materials (CloCu-1, CloCu-2, CloCu-3, $\mathrm{CloCu}-4$ and $\mathrm{CloCu}-5)$, respectively, was clearly observed in all the samples. However, it is noteworthy that the zone of inhibition of the organoclay/Cu hybrid materials is generally increased when the organoclay loading is increased. Greater antibacterial effect can be largely observed on the $P$. aeruginosa plates since they show increased zone of inhibition as compared to the E. coli plates. Organoclay/Cu hybrid materials showed a more effectiveness as antibacterial agent to $P$. aeruginosa bacteria as compared to the $E$. coli bacteria. All the organoclay/ $\mathrm{Cu}$ compounds showed higher inhibition rates against the tested microorganisms suggesting that these hybrid materials are effective antibacterial agents. $\mathrm{Cu}$ nanoparticles without addition of organoclay were also used as a reference and it also showed antibacterial activity as demonstrated by the zone of inhibition. The higher antibacterial activity of the $\mathrm{Cu}$ nanoparticles is observed with the $P$. aeruginosa microorganisms as compared to the $E$. coli. As compared 

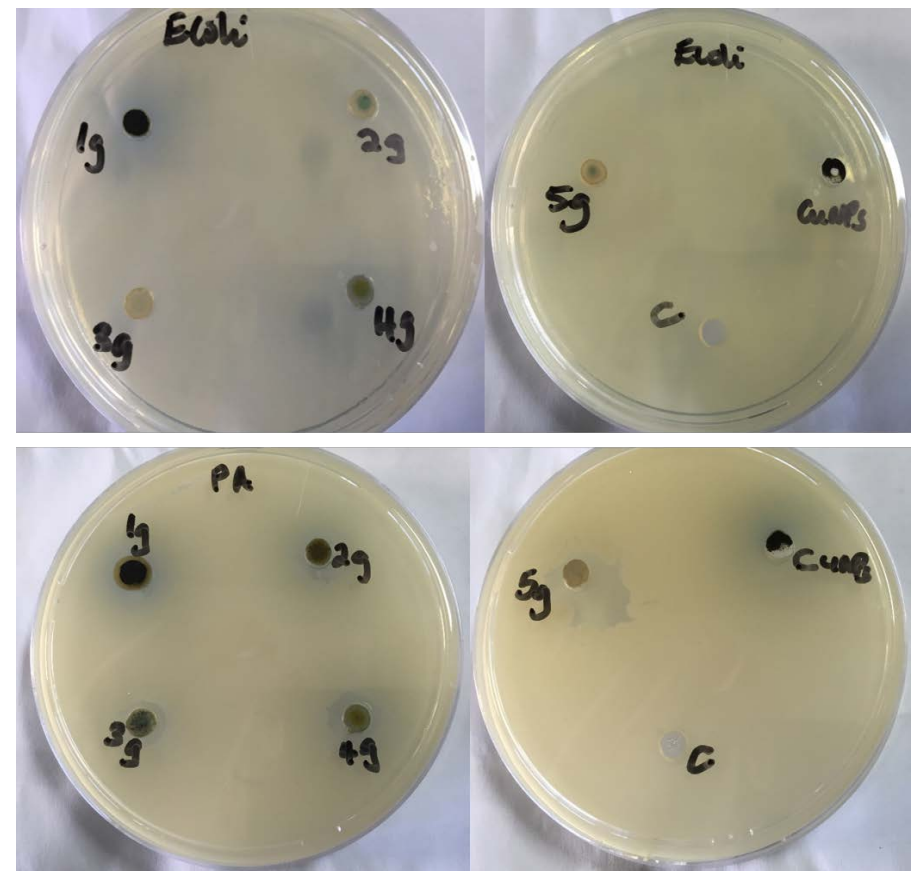

Figure 6. Antimicrobial activity of as-synthesized organoclay/Cu hybrid materials Clo$\mathrm{Cu}-1, \mathrm{CloCu}-2, \mathrm{CloCu}-4$ and $\mathrm{CloCu}-5$ against two gram-negative bacteria using the disk diffusion method.

with the organoclay/Cu hybrid antibacterial activity, $\mathrm{Cu}$ nanoparticles showed higher bactericidal effect with the $P$. aeruginosa microorganism than with the $E$. coli, in which the hybrid showed a higher activity.

The bacterial effect of metal nanoparticles has been attributed to their size and high surface to volume ratio, which allows them to interact with microbial membranes and is not merely due to the release of metals ions in solution as reported previously by Jung et al. [44]. The CloCu-5, which has the highest organoclay concentration, was determined to be optimal, due to its higher activity against the microbial species tested. This can be attributed to the smaller size of copper nanoparticles formed as observed in the TEM micrographs results shown above.

\section{Conclusion}

Copper nanoparticles supported on organoclay surfaces were successfully synthesized via a chemical method. The organoclay material acted as a good support for nanoparticles formation. Transmission electron micrographs for the $\mathrm{CloCu}$ 5 , the highest organoclay loading, indicate the size of the nanoparticles to be smaller as compared with the other hybrid materials. XRD data showed that the copper nanoparticles formed contained a mixture of $\mathrm{Cu}^{\circ}$ and $\mathrm{Cu}_{\mathrm{x}} \mathrm{O}_{\mathrm{y}}$ crystalline phases. The antimicrobial activity of the nanoparticles was determined according to the organoclay loading using a couple of bacterial species. The CloCu-5, which is the highest organoclay concentration, was determined to be optimal, due to its higher activity against the microbial specie tested. This can be attributed to the smaller size of nanoparticles formed as observed in the TEM mi- 
crographs. Our results indicate the future potential of these organoclay/Cu hybrids materials for combating pathogenic microorganisms. Further work still needs to be carried out (in vivo studies) to determine the toxicity of these nanomaterials which will allow for the application and use of these nanoparticles.

\section{Acknowledgements}

M. F. B. would like to thank DST/Mintek Nanotechnology Innovation Center to allow the publication of this work.

\section{References}

[1] Lu, W. and Lieber, C.M. (2007) Nanoelectronics from the Bottom up. Nature Materials, 6, 841-850. https://doi.org/10.1038/nmat2028

[2] Karni, T.C., Langer, R. and Kohane, D.S. (2012) The Smartest Materials: The Future of Nanoelectronics in Medicine. ACS Nano, 6, 6541-6545. https://doi.org/10.1021/nn302915s

[3] Rau, I., Grote, J.G. and Pawlicka, F.K.A. (2012) DNA-Novel Nanomaterial for Applications in Photonics and Electronics. Comptes Rendus Physique, 13, 853-864.

[4] Wei, C. and Zhao, Y.S. (2016) Photonic Applications of Metal-Dielectric Heterostructured Nanomaterials. ACS Applied Materials \& Interfaces, 8, 3703-3713. https://doi.org/10.1021/acsami.5b08086

[5] Xu, T.T. and Lee, J. (2014) Nanomaterials: Electrical, Magnetic, and Photonic Applications. Journal of Management, 66, 654.

https://doi.org/10.1007/s11837-014-0923-1

[6] Kalidindi, S.B. and Jagirdar, B.R. (2012) Nanocatalysis and Prospects of Green Chemistry. ChemSusChem, 5, 65-75. https://doi.org/10.1002/cssc.201100377

[7] Chen, Z.H., Jie, J.S., Luo, L.B., Wang, H., Lee, C.S. and Lee, S.T. (2007) Applications of Silicon Nanowires Functionalized with Palladium Nanoparticles in Hydrogen Sensors. Nanotechnology, 18, 345502-34507. https://doi.org/10.1088/0957-4484/18/34/345502

[8] Lewis, L.N. (1993) Chemical Catalysis by Colloids and Clusters. Chemical Reviews, 93, 2693-2730. https://doi.org/10.1021/cr00024a006

[9] Etheridge, M.L., Campbell, S.A., Erdman, A.G., Haynes, C.L., Wolf, S.M. and McCullough, J. (2013) The Big Picture on Nanomedicine: The State of Investigational and Approved Nanomedicine Products. Nanomedicine: Nanotechnology, Biology, and Medicine, 9, 1-14.

[10] Salata, O.V. (2004) Applications of Nanoparticles in Biology and Medicine. Journal of Nanobiotechnology, 2, 15-20.

[11] Narayan, R. (2010) Use of Nanomaterials in Water Purification. Materials Today, 13, 44-46.

[12] Qu, X., Alvarez, P.J.J. and Li, Q. (2013) Applications of Nanotechnology in Water and Wastewater Treatment. Water Research, 47, 3931-3946.

[13] Gehrke, I., Geiser, A. and Somborn-Schulz, A. (2015) Innovations in Nanotechnology for Water Treatment. Nanotechnology, Science and Applications, 8, 1-17. https://doi.org/10.2147/NSA.S43773

[14] Gentile, A., Ruffino, F. and Grimaldi, M.G. (2016) Complex-Morphology MetalBased Nanostructures: Fabrication, Characterization, and Applications. Nanomaterials, 6, 110-118. https://doi.org/10.3390/nano6060110 
[15] Bastús, N.G., Merkoçi, F., Piella, J. and Puntes, V. (2014) Synthesis of Highly Monodisperse Citrate-Stabilized Silver Nanoparticles of up to $200 \mathrm{~nm}$ : Kinetic Control and Catalytic Properties. Chemistry of Materials, 26, 2836-2846. https://doi.org/10.1021/cm500316k

[16] Creighton, J., Blatchford, C. and Albrecht, M. (1979) Plasma Resonance Enhancement of Raman Scattering by Pyridine Adsorbed on Silver or Gold Sol Particles of Size Comparable to the Excitation Wavelength. Journal of the Chemical Society, Faraday Transactions, 75, 790-798. https://doi.org/10.1039/f29797500790

[17] Kholoud, M.M., El-Noura, A., Eftaihab, A., Al-Warthanb, A. and Ammar, R.A.A. (2010) Synthesis and Applications of Silver Nanoparticles. Arabian Journal of Chemistry, 3, 135-140.

[18] Liu, H. and Toshima, N. (1992) Transferring Colloidal Metal Particles from an Organic to an Aqueous Medium and Vice Versa by Ligand Coordination. Journal of the Chemical Society, Chemical Communications, 1095-1096.

https://doi.org/10.1039/c39920001095

[19] Mittal, A.K., Chisti, Y. and Banerjee, U.C. (2013) Synthesis of Metallic Nanoparticles Using Plant Extracts. Biotechnology Advances, 31, 346-356.

[20] Cioffi, N., Torsi, L., Ditaranto, N., Tantillo, G., Ghibelli, L., Sabbatini, L., BleveZacheo, T., D’Alessio, M., Zambonin, P.G. and Traversa, E. (2005) Copper Nanoparticle/Polymer Composites with Antifungal and Bacteriostatic Properties. Chemistry of Materials, 17, 5255-5262. https://doi.org/10.1021/cm0505244

[21] Deryabin, D.G., Aleshina, E.S., Vasilchenko, A.S., Deryabina, T.D., Efremova, L.V., Karimov, I.F. and Korolevskaya, L.B. (2013) Investigation of Copper Nanoparticles Antibacterial Mechanisms Tested by Luminescent Escherichia coli Strains. Nanotechnologies in Russia, 8, 402-408. https://doi.org/10.1134/S1995078013030063

[22] Blinova, I., Ivask, A., Heinlaan, M., Mortimer, M. and Kahru, A. (2010) Ecotoxicity of Nanoparticles of $\mathrm{CuO}$ and $\mathrm{ZnO}$ in Natural Water. Environmental Pollution, 158, 41-47.

[23] Cao, V.D., Nguyen, P.P., Khuong, V.Q., Nguyen, C.K., Nguyen, X.C., Dang, C.H. and Quyen, N. (2014) Ultrafine Copper Nanoparticles Exhibiting a Powerful Antifungal/Killing Activity against Corticium Salmonicolor. Bulletin of the Korean Chemical Society, 35, 2645-2648. https://doi.org/10.5012/bkcs.2014.35.9.2645

[24] Kanhed, P., Birla, S., Gaikwad, S., Gade, A., Seabra, A.B., Rubilar, O., Duran, N. and Rai, M. (2014) In Vitro Antifungal Efficacy of Copper Nanoparticles against Selected Crop Pathogenic Fungi. Materials Letters, 115, 13-17.

[25] Kalatehjaria, P., Yousefi, M. and Khalilzadeh, M.A. (2015) Assessment of Antifungal Effects of Copper Nanoparticles on the Growth of the Fungus Saprolegnia sp. on White Fish (Rutilus frisii kutum) Eggs. The Egyptian Journal of Aquatic Research, 41, 303-306.

[26] Sankar, R., Maheswari, R., Karthik, S., Shivashangari, K.S. and Ravikumar, V. (2014) Anticancer Activity of Ficus religiosa Engineered Copper Oxide Nanoparticles. Materials Science and Engineering C, 44, 234-239.

[27] Vinardell, M.P. and Mitjans, M. (2015) Antitumor Activities of Metal Oxide Nanoparticles. Nanomaterials, 5, 1004-1021. https://doi.org/10.3390/nano5021004

[28] Palashuddin, M.D., Goswami, U., Ghosh, S.S. and Chattopadhyay, A. (2015) $\mathrm{Cu}^{2+}$ Embedded Carbon Nanoparticles as Anticancer Agents. Journal of Materials Chemistry B, 3, 5673-5677. https://doi.org/10.1039/C5TB00567A

[29] Umer, A., Naveed, S., Ramzan, N. and Rafique, M.S. (2012) Selection of a Suitable Method for the Synthesis of Copper Nanoparticles. Nano: Brief Reports and Reviews, 7, 1230005-1230023. https://doi.org/10.1142/S1793292012300058 
[30] Drelich, J., Li, B., Bowen, P., Hwang, J.-Y., Mills, O. and Hoffman, D. (2011) Vermiculite Decorated with Copper Nanoparticles: Novel Antibacterial Hybrid Material. Applied Surface Science, 257, 9435-9443.

[31] Hundáková, M., Valášková, M., Tomášek, V., Pazdziora, E. and Matějová, K. (2013) Silver and/or Copper Vermiculites and Their Antibacterial Effect. Acta Geodynamica et Geomaterialia, 10, 97-104.

[32] Samim, M., Kaushik, N.K. and Maitra, A. (2007) Effect of Size of Copper Nanoparticles on Its Catalytic Behaviour in Ullman Reaction. Bulletin of Materials Science, 30, 535-540. https://doi.org/10.1007/s12034-007-0083-9

[33] Bhattacharya, S.S. and Mandot, A. (2014) Studies on Preparation and Analysis of Organoclay Nano Particles. International Journal of Engineering Science, 3, 10-16.

[34] Lee, Y., Choi, J.R., Lee, K.J., Stott, N.E. and Kim, D. (2008) Large-Scale Synthesis of Copper Nanoparticles by Chemically Controlled Reduction for Applications of Inkjet-Printed Electronics. Nanotechnology, 19, Article ID: 415604. https://doi.org/10.1088/0957-4484/19/41/415604

[35] Khan, A., Rashid, A., Younas, R. and Chong, R. (2016) A Chemical Reduction Approach to the Synthesis of Copper Nanoparticles. International Nano Letters, 6, 21 26. https://doi.org/10.1007/s40089-015-0163-6

[36] Suleiman, M., Mousa, M., Hussein, A., Hammouti, B., Hadda, T.B. and Warad, I. (2013) Copper (II)-Oxide Nanostructures: Synthesis, Characterizations and their Applications-Review. Journal of Materials and Environmental Science, 4, 792-797.

[37] Qian, Y., Ye, F., Xu, J. and Le, Z.-G. (2012) Synthesis of Cuprous Oxide $\left(\mathrm{Cu}_{2} \mathrm{O}\right) \mathrm{Na}$ noparticles/Graphene Composite with an Excellent Electrocatalytic Activity towards Glucose. International Journal of Electrochemical Science, 7, 10063-10073.

[38] Nasirian, A. (2012) Synthesis and Characterization of $\mathrm{Cu}$ Nanoparticles and Studying of Their Catalytic Properties. International Journal of Nano Dimension, 2, 159164.

[39] Murugadoss, G., Rajamannan, B. and Madhusudhanan, U. (2009) Synthesis and Characterization of Water-Soluble ZnS: Mn2+ Nanocrystal. Chalcogenide Letters, 6, 197-201

[40] Petrova, I., Ivanov, E. and Kotsilkova, R. (2015) Structure and Properties of Polypropylene Containing Organo-Clay and Carbon Nanotubes as Fillers. Bulgarian Chemical Communications, 47, 95-102.

[41] Hadj-Hamou, A.S., Matassi, S., Abderrahmane, H. and Yahiaoui, F. (2014) Effect of Cloisite $30 \mathrm{~B}$ on the Thermal and Tensile Behavior of Poly (Butylene Adipate-coTerephthalate)/Poly (Vinyl Chloride) Nanoblends. Polymer Bulletin, 71, 1483-1503. https://doi.org/10.1007/s00289-014-1137-y

[42] Kayani, Z.W., Umer, M., Riaz, S. and Naseem, S. (2015) Characterization of Copper Oxide Nanoparticles Fabricated by the Sol-Gel Method. Journal of Electronic Materials, 44, 3704-3709. https://doi.org/10.1007/s11664-015-3867-5

[43] Kobayashia, Y., Abea, Y., Maedaa, T., Yasudab, Y. and Morita, T. (2014) A MetalMetal Bonding Process Using Metallic Copper Nanoparticles Produced by Reduction of Copper Oxide Nanoparticles. Journal of Materials Research and Technology, 3, 114-118.

[44] Jung, W.K., Koo, H.C., Kim, K.W., Shin, S., Kim, S.H. and Park, Y.H. (2008) Antibacterial Activity and Mechanism of Action of the Silver Ion in Staphylococcus aureus and Escherichia coli. Applied and Environmental Microbiology, 74, 21712178. https://doi.org/10.1128/AEM.02001-07 
Submit or recommend next manuscript to SCIRP and we will provide best service for you:

Accepting pre-submission inquiries through Email, Facebook, LinkedIn, Twitter, etc. A wide selection of journals (inclusive of 9 subjects, more than 200 journals) Providing 24-hour high-quality service

User-friendly online submission system

Fair and swift peer-review system

Efficient typesetting and proofreading procedure

Display of the result of downloads and visits, as well as the number of cited articles Maximum dissemination of your research work

Submit your manuscript at: http://papersubmission.scirp.org/

Or contact jbnb@scirp.org 